\title{
The Verbal System of English and Albanian Passive Voice
}

\author{
Prof. Ass. Dr. Shpresë Qamili \\ Vice-Rector for Academic Affairs \\ Public University "Kadri Zeka" \\ St."Zija Shemsiu”, post code 60000 - Gjilan \\ Republic of Kosovo
}

\begin{abstract}
This study distinguishes the main features of English passive voice in general and how do its verbs reflect in Albanian in particular. Seeing the nature of the topic and its complexity, we reasonably argue that it is not easy to shed light on the problems of the verbal system of the English passive voice in the Albanian language, because difficulties arise for the contrastive linguistics even for the scholars of linguistic field in the fact that comparative studies on contrastive linguistics have a complex pathway. It is said because we still lack the proper analytical studies which would indicate the paths of the researchers results of this language discipline. This study is intended to give our modest contribution to notice the similarities and differences in the use of the passive voice as well as its structure in both languages. This contrastive analysis tries to facilitate the acquisition of English as a foreign language for students, pupils, to make the translation from English into Albanian and vice versa easier, to provide linguistic information to language researchers. The comparison is supported by the following English novels and their translated versions in Albanian such as: "Oliver Twist" by Charles Dickens and translated by Skënder Luarasi and "Silas Marner" by George Eliot and translated by Ramazan Hysa, where similar as well as different features have been found.
\end{abstract}

Keywords: verb. voice; passive; structural; preposition.

\section{Introduction}

It is well known that comparative linguistics, as one of the major branches of general linguistics, is an explanatory science that seeks to clarify the fact that the languages, above all, are related to one another.

Thus, over the centuries, starting from the 19th century to the present day, in both Europe and other continents, these linguistic processes have yielded some satisfactory results, but never high results in the grammatical, syntax system and vocabulary neither in terms of the development of comparative methods nor to the theoretical results, which would testify to what extent the mutual application between these two languages was made and can be done.

Seeing the nature of the topic and its complexity, we reasonably argue that it is not easy to shed light on the problems of the verbal system of the English passive voice in the Albanian language, because difficulties arise for the contrastive linguistics even for the scholars of linguistic field in the fact that comparative studies on contrastive linguistics have a complex pathway. It is said because we still lack the proper analytical studies which would indicate the paths of the researchers results of this language discipline.

It is understood that prominent linguistic minds brought their contribution and the illumination of the English language connection to other languages, even though they passed through difficult scientific paths. The number of linguists that are considered initiators and first comparative activists in the history of linguistics are, in our opinion, few, compared to the number of researchers in other scientific fields. The problem becomes more pronounced when we add to the data that even the Albanian language as an Indo-European language with its linguistic values in the field of morphology and syntax has widened the curiosity of the different linguists of Europe, both of the English and the Albanian linguists for English language. In illuminating such problems, according to the literature, it is learned that for linguists, though at first the results will not be complete and synthetic, the efforts will be praised and appreciated, because it characterizes the connections and reflections of the English language with that of the Albanian even in the field of the verb as a grammatical category through the application of the comparative method.

However, studies and emerged outcomes in terms of similarities of the English passive voice in Albanian are done in different forms and that these links tend to be factual with an emphasis on the objectivity of the comparative linguistics. It is considered that these linguists efforts were developed as a process, as examples, as a comparison and contrast, as a classification, as a definition, and ultimately as a cause-effect. 
It became clear that in the lightening of these aspects of the verbal system of the passive voice within these two languages, it would not be right to prefer the form, let's call it, as it has become a rule to pronounce among linguists, synthetic-of linguistic similarities-synthesis, to what is shown, decomposed, viewed a problem, a phenomenon, a linguistic historical phenomenon, thus, the method of generalization with analysis; modern linguistics proves that there are many examples achieved through other ways of deploying the most diverse methods.

From this point of view, it turns out that opportunities and alternatives in lightening the structure of the usage of the English passive voice in Albanian are numerous. For example, in this complex problem a linguistic support has given deduction and induction. By bringing examples of special support for generalization, linguists have succeeded in bringing thoughts and conclusions through the shifting of thoughts from general issues and problems to particular ones. The next time, linguists have used induction because during the treatment of the usage problems of English passive voice in Albanian, it was the need to present particular occurrences that have led to generalization or formulated thesis. The language as it is said by the most prominent linguists is beautiful if it is traversed by varied grammatical forms, that is, of the verbal system as well. This becomes even clearer when we add to the data that languages maintain and deepen the grammatical connections among them.

With the development of contrastive linguistics from the 1928s, Viliem Mathesius noted that "systematic analysis of any language can only be achieved on a strict synchronous basis and with the help of an analytical comparison, it means a comparison of different types of languages and without any genetic connection among them".

Such an estimation by Mathesius and his methodology in shedding light even in the field of the verbal system will also find support from the well-known scholar and teacher W. S. Mackey in 1965.

In the course of these scholars, there will be other scholars who in various ways indicate linguistic issues under contrastive analysis such as Charles Ferguson (1968), Ronald Wardhaugh (1974), Lado (1957), Fries (1945) and some others.

Concluding this introduction, it can be added that during the research, it has been shown that the problem of using the English and Albanian passive voice not only to see the intersections in concrete cases in the modes of action but to trace and see concrete cases of manifestation of the expression of the passive voice between these two languages.

In the end, it is emphasized that with the dedication shown for the Albanian language, the results achieved within the paper will awaken the interest of the linguists and will encourage them to further advance the treatment of the topic, which will of course extend knowledge on abovementioned problems.

In this paper, without pretending to give a thorough study of this problem, it is considered necessary to point out some of the characteristic features and phenomena of the problem, such as: definition of the passive voice, passive auxiliary verbs 'be' and 'get'; passive auxiliary verbs 'be' and 'get' and bare passive; the structural distinction between active and passive sentences; passive verbs with preposition and verbs that are used in passive voice.

\section{Definition of the passive voice}

The phenomenon of voice, particularly of the relation between active and passive has played an important role in the development of modern linguistics. Although the structure of passive is no longer considered as a monolithic phenomenon in transformative grammar, it is still characterized as a participant of the original form of the transformational movement, the only transformation now known in Chomskyian grammar of principles and parameters (Shibatani, 1988).

Based on the researched literature, the definition of voice will be given, according to which voice is a verb category which indicates whether the subject is the doer or the receiver of the action. According to this, there are two voices, active and passive voice.

The active voice shows the action done by the subject, it means the subject is the doer of the action.

\section{Picasso painted the picture.}

Pikasoja pikturoi pikturën.

The passive voice indicates that the subject in a sentence is acting upon a verb.

The picture was painted by Picasso. Piktura ishte pikturuar nga Pikasoja.

Thus, the division into voices is based on the action expressed by the verb (predicator) and the doers or receivers of the action expressed by the subject.

The general term voice is dedicated to a system where contradictory forms differ in such ways as semantic roles associated with syntax functions, of course with some accompanying verbs. In the first example, the sentence is in active voice because the subject of this sentence: Picasso is the doer of the action, Picasso performs the action. 
In the second example, the sentence is in passive voice, because the subject The picture has a passive role. The receiver of the action is the one that is acting upon. The element of the sentence in active voice which represents the receiver of the action is the object that is realized by a noun phrase or a structure with nominal function. When the verb is changed into passive, the object of the active verb becomes the subject of the passive sentence. The subject of the active sentence as a doer of the action becomes the object of the passive sentence with the preposition by (nga). The subject of the active sentence expressed in this way is called a converted subject which in most cases remains unexpressed. This transformation process can be symbolized as follows:

NP1+VPactive+NP2 NP2+VPpassive+(byNP1) (Quirk \& Greenbaum, 2003:160)

The passive verb phrases are less common and used for specific discourse functions. They reduce the importance of the doer and complement other functions of discourse.

The passive voice is an analytic form in modern English; It is composed of two elements:

the appropriate form of the verb 'to be' + past participle.

However, the passive verb phrases can also be formed with the auxiliary verb get called passive-get.

President Kennedy was shot in 1963.

It's about these people who got left behind in Vietnam. (Bober, Conrad \& Leech, 2002:166)

The passive voice is possible with most transitive verbs. The noun phrase-subject in passive sentence usually corresponds with the direct object in the equivalent active sentence. (Bober, Conrad \& Leech, 2002:166)

Passives may also appear as short or long passives. In short passives also called passives without a doer, the doer is not specified. Thus, in the first example below, it is not stated who exactly discovered the traces of ice on Mars. Similar to example 2, the doer is someone unspecified.

Traces of ice have been discovered on the surface of Mars

The dog was punished for the misbehaviour.

Long passives contain the phrase with by (nga, prej), which typically specifies the doer of the action. In some cases, the phrase with by will specify a different semantic role as the receiver of the experience. (Bober, Conrad \& Leech, 2002:167)

Research will be presented by Jim at the conference.

Results will be published by the professor in the students' journal.

Short passives are about six times more frequent than long passives.

The subject of the passive verb can also correspond with the indirect object of the ditransitive verbs. ${ }^{1}$

They gave John the first prize. (active voice)

John was given the first prize. (passive voice)

The first prize was given to John. (passive voice)

Or the object with a prepositional verb. (Bober, Conrad \& Leech, 2002:167)

The problem was very carefully gone into by the engineers.

The expected result was eventually arrived at. (Quirk \& Greenbaum, 2003:163)

Most of the passive verbs are easy to be identified. However, sometimes some structures look like passive verbs, but are adjectives that describe state or quality. (Bober, Conrad \& Leech, 2002:167)

We are delighted with the result.

I ought to be excited. (Bober, Conrad \& Leech, 2002:167)

\section{Passive auxiliary verbs: $\underline{\text { be }}$ and get}

In the abovementioned sentences, it was said that the English passive voice is composed of the appropriate form of the auxiliary verb 'to be' + past participle. This structure (with 'be') is used more often that the auxiliary verb 'get'. The auxiliary verb 'get' is rarely used or is more used in conversations than in formal writing. It is known as the result copula which can not be expanded with an agent in the passive sentences:

My baby will get dressed by me.

Foshnja ime do të jetë veshur nga unë.

The text got translated by him yesterday.

Teksti u përkthye nga ai dje.

He got hit while he was playing.

Ai u godit derisa ishte duke luajtur.

\footnotetext{
${ }^{1}$ We used the term ditransitive from English for the verbs that take two objects.
} 
With the help of the auxiliary verb 'get' the passive sentence is more dynamic including the process of undergoing that state.

The thief was caught stealing some jewelery at a shop.

Hajni u zu duke vjedhur ca gurë të çmueshëm në një shitore.

The mouse got caught eating some cheese on dhe table.

Міи и zи duke ngrënё ca djathë mbi tavolinë.

The passive voice formed with the auxiliary verb 'get' seems to have more frequent use in the spoken language.

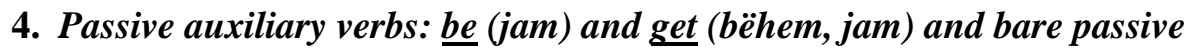

It is noticed that the active verb appears in the form of past participle in passive voice (Huddleston \&Pullum, 2002:1427).

Bill writes the reports.

Billi i shkruan raportet.

The reports are written by Bill.

Raportet shkruhen nga Billi. $\quad$ (passive voice)

Not all the passive sentences have the verb 'be'; some have the verb 'get'; there are also some passives that do not have any of these verbs. They are called bare passives. (Huddleston \&Pullum, 2002:1430). Let's make a comparison according to (Huddleston \& Pullum, 2002:1430):

Jack was mauled by our neighbour's dog.

Jack got mauled by our neighbour's dog.

He saw Jack mauled by our neighbour's dog...

The gay mauled by neighbour's dog...

\author{
[passive - be] \\ [passive-get] \\ [bare passive] \\ [bare passive]
}

Bare passives do not usually have any obvious subject like Jack (3), which is syntactically an object. Below you may see the examples where the bare passive does not have an obvious subject (Huddleston \&Pullum, 2002:1430):

All things considered, we're lucky not to have been sued for a lot more. (short)

People really are inconsiderate - present company expected. (short)

My Mouse wrecked by a tornado as something I don't ever want to see. $\quad$ (long)

Their vehicle immobilized by the mud, they had to escape on foot. (long)

Because of the past participle verb, such sentences are always non-finite and hence limited only to the subordinate position. The passive main sentences contain either the 'be' or 'get' (Huddleston \&Pullum, 2002:1430)

\section{The structural difference between the active and passive sentences}

Whether the English sentences are in active voice or passive voice is also determined by their syntactic features. From a syntactic point of view, formal oppositions active - passive differ in four summarized ways, as it is illustrated below:
The boss approved the plan.
(active voice)
Shefi miratoi planin.
The plan was approved by the boss. $\quad$ (passive voice)
Plani u miratua nga shefi.
The doctor examined the patient (Susan). (active voice)
Mjeku shëroi pacienten (Suzanën).
The patient was examined by the doctor. (passive voice)
Pacientja u shërua nga mjeku.

1. The subject of the active sentence (mjeku - the doctor) is presented as a complement with the preposition (by-nga) in passive sentence and generally it is not an obligatory element, (Huddleston \&Pullum, 2002:1428)

2. The object of the active sentence (the pacient - pacientja) becomes the subject of the passive sentence, (Huddleston \&Pullum, 2002:1428)

3. The active verb appears in the form of past participle in passive voice. (examined), (Huddleston \&Pullum, 2002:1428)

4. The passive has also a supplementary verb, the auxiliary verb be (jam), (Huddleston \&Pullum, 2002:1428)

\section{Prepositional verbs as passives}

They laughed at the actor
The parents sent for the doctor.
They talked about her all over the town 


\title{
The actor was laughed at. $\quad$ (passive voice) \\ The doctor was sent for \\ She was talked about all over the town.
}

The underlined noun phrases in the examples of active voice are not objects of the verb but objects of the preposition. In passive voice, this phrase functions as subject.

The prepositional verbs can often appear in passive voice but not as freely as in the active voice; most of them are used in the passive voice only in figurative sense:

The scientists arrived at the expected result.

The expected result was arrived at.

\author{
(active voice) \\ (passive voice)
}

\section{Verbs that are used in the passive voice}

As mentioned above, to form the passive voice, the verb should be transitive:

- Monotransitive verbs that take only one object: a direct object. ${ }^{2}$

- Ditransitive verbs that take both direct objects and indirect objects.

- Complex transitive verbs that require both a direct object and an object complement.

- Other transitive verbs that take a direct object and an adjunct.

Monotransitive verbs - the object of the active sentence becomes the subject of the passive sentence. Ditransitive verbs - the direct or indirect object of the active sentence becomes the subject of the passive sentence, but in most cases the indirect object becomes the subject of the passive sentence. Complex transtive verbs and other transitive verbs - the same object becomes the subject of the passive sentence. In the following examples, it is noticed that when the active sentence has two objects, they can become subjects in the passive sentence:

\section{She showed me her photographs. (active voice)}

I was showed her photographs (by her). (passive voice)

Her photographs were showed me (by her). (passive voice)

They gave me some books.

I was given some books (by them). Some books were given me (by them).

She gave him a kiss.

He was given a kiss(by her).

A kiss was given him (by her).

\author{
(active voice) \\ (passive voice) \\ (passive voice) \\ (active voice) \\ (passive voice) \\ (passive voice)
}

Not all verbs can be used in passive voice. Only transitive verbs which are followed by an object can be turned into passive voice.

The reasons for using the passive voice are:

- The doer of the action is unimportant.

- The doer of the action is unknown.

- The doer of the action is known but it is excessive to be mentioned.

Voice can be recognized through the use of 'double verb' and is formed using the appropriate form of the verb 'to be' + past participle. The past participle of regular verbs is formed by adding the suffix 'ed' while irregualr verbs have special past participle forms.

\section{Conclusion}

The structure and use of the English and Albanian passive voice is an important issue, both for the spoken and written forms, or in terms of the extension of this gramatical category of verb in general. The interest in seeing grammatical category reports of passive voice within English and Albanian languages is long-lasting. Therefore, during the research work, it has been tried, both in conceptual and methodological terms, to concentrate on the investigation and treatment of those important elements that in depth will reveal the structure and content of the topic.

Moreover, in observing the relevant phenomena of the structure and use of the passive voice in English and Albanian, our objective has been to attempt to see the various and numerous elements of the passive voice, which in different ways and forms are reflected in English and Albanian language.

\footnotetext{
${ }^{2}$ We used the term monotransitive from English for the verbs that take one object
} 
It is recalled that the structure and use of the passive vocie, not only to me, but also to many researchers and linguists, has awakened, has revived interest, who, it is thought, will significantly advance the achievements and results in the direction of lightening the phenomena and the most acute issues of the topic. To look at the above topic, to search passive voice through the texts of English and Albanian writers, to discover concrete examples of usage means to synthesize the so far achievements in the field of study on a comparative basis and to discuss and solve a number of important issues around this topic.

\section{References}

Bober, D. Conrad, S. \& Leech, G. (2002). "Student Grammar of Spoken and Written English", Pearson Education, Harlow.

Ferguson, C. (1968). „Language development“. In Fishman, Joshua A. \& Charles A. Ferguson \& Jyotirindra Das Gupta (eds.): Language Problems of Developing Nations. New York, London et al.: John Wiley \& Sons. 27-36.

Fries, C. (1945). "Teaching and Learning English as a Foreign Language". Ann Arbor: University of Michigan Press.

Huddleston, R. \& Pullum, G. (2002). "The Cambridge Grammar of the English Language", Cambridge University Press, Cambridge.

Lado, R. (1957). "Linguistics across cultures", Ann Arbor - The University of Michigan Press.

Quirk, R. \& Greenbaum, S. (2003). "A Comprehensive Grammar of the English Language", Pearson Education, Harlow.

Shibatani, M. (1988). "Passive and Voice", Amsterdam/Philadelphia.

Wardhaugh, R. (1974). "Introduction to Linguistics", New York: McGraw Hill. 